\section{High-volume surgery in developing countries}

D Yorston

There is no simple definition of high-volume

Abstract

Background Cataract remains the world's leading cause of blindness. In the developing world, many eye clinics provide cataract surgery for only a small proportion of those in need. This is partly because of low demand - caused by barriers related to awareness, bad services, cost, and distance - and partly because of deficiencies in the supply of services. This article reviews innovations in cataract surgery in poor countries that are intended to reverse this trend.

Conclusions Increasing the number of operations, through close involvement with the community, and improved surgical outcomes, enables the cost of surgery to be reduced, leading to further growth in volume. Recent innovations, such as low-cost intraocular lenses, and small-incision extracapsular cataract extraction, have contributed to improving the results of surgery without increasing the costs. Effective management enables the delivery of increasing the numbers of operations, while at the same time improving outcomes and controlling costs.

Eye (2005) 19, 1083-1089. doi:10.1038/sj.eye.6701966

Keywords: cataract extraction; intraocular lens; health-care costs; outcome assessment; community participation

\section{Introduction}

Approximately 10 million cataract operations are carried out every year. If global cataract blindness is to be eliminated, this must increase to 30 million by 2020, and most of that increase must take place in the poorest countries of Africa, Asia, and Latin America. ${ }^{1-3}$ surgery that is applicable everywhere. A total of 1000 surgeries per year would be high volume in Africa or Latin America, but not in India. In this paper, a high-volume clinic is one that carries out significantly more surgeries than other centres in the same region.

In order to provide high-volume cataract surgery, both the demand for surgery and the supply of services must be addressed. In most developing countries the cataract surgery rate (CSR; no. of cataract operations/million population/year) is less than 1000. It is estimated that a CSR of between 2000 and $4000^{4}$ is necessary to eliminate cataract as a major cause of blindness. This means that there is a large and unmet need for cataract surgery in most developing countries. ${ }^{2}$ However, this stems more from a lack of demand than from inadequate supply.

\section{Demand}

There are four major barriers that deter people from seeking cataract surgery. These are awareness, bad services, cost, and distance. In order to increase demand, every barrier must be reduced. Unfortunately, there is little published research to confirm the efficacy of most strategies intended to boost demand for cataract surgery.

\section{Awareness}

Studies in Nepal, ${ }^{5}$ India, ${ }^{6}$ and Nigeria ${ }^{7}$ show that people are not aware of the benefits of cataract surgery. Cataract blindness is more common in poor, rural, and illiterate patients than in wealthy urban and educated individuals. Even where people are aware of surgery, they may not know how to obtain treatment, or they may not believe it will be effective. In communities where cataract
Moorfields Eye Hospital, Vitreo-retinal Service, London, UK

Correspondence: D Yorston, Moorfields Eye Hospital, Vitreo-retinal Service, City Road, London EC1V 2PD, UK

Tel: + 442083689359 ;

Fax: + 442078863259

E-mail: dhyorston@

enterprise.net

Received: 14 April 2005 Accepted: 2 May 2005 
surgery has only recently become available, deteriorating vision is regarded as an inevitable part of aging. Patients who are still able to care for themselves may regard cataract surgery as unnecessary. Most of this research was carried out when the standard cataract operation was intracapsular cataract surgery, with no intraocular lens (IOL) implant. Where IOL implantation is routine, and the quality of unaided postoperative vision is good, the number of cataract operations increases. It may be that patients were telling us that our services were simply not good enough.

\section{Overcoming the awareness barrier}

This can be achieved by members of the patients' own communities, who speak their language and understand their beliefs. Primary health-care workers should be able to provide this service. In practice, however, the priority for most primary health-care programmes in poor communities is improving child survival. They focus on nutrition, immunisation, ante-natal care, and early treatment of acute infections. This means that primary health-care workers are rarely in contact with elderly patients with chronic painless loss of vision.

An alternative approach is to train community workers who have the specific task of identifying cataract patients, and facilitating their referral to hospital. They may be health workers, or people who have themselves had cataract surgery. ${ }^{6}$ This can be done by going house to house, or by organising screening eye camps. One study showed that using previously operated cataract patients was the most cost-effective means of identifying and motivating people in need of cataract surgery. ${ }^{8}$ Whatever approach is used, close co-operation between the community and the eye care provider is essential. ${ }^{9}$

The use of the mass media, particularly radio, to promote cataract surgery, has been effective in some countries. The author has treated patients who have travelled over $500 \mathrm{~km}$ to attend an eye clinic that they heard advertised on the BBC World Service. In future, social marketing of cataract surgery may raise awareness to the point that community-based case finding is no longer necessary.

\section{Bad service}

Bad service was given as a reason for avoiding cataract surgery in Nigeria. ${ }^{7}$ One obvious indicator of a poor service is poor postoperative vision. However, this is not the only determinant, as some patients in Nigeria were willing to risk couching. In a traditional society the elderly are accustomed to receiving respect. As visually impaired patients they are dependent on others, and may even be denigrated. Rudeness by staff, or demands for bribes, are even more likely to deter patients than poor surgical outcomes.

\section{Overcoming the bad service barrier}

Accountability of staff is critical to developing a successful high-volume programme. In government hospitals, this may be difficult to achieve, which is why many high-volume clinics are run by non-government organisations. Where cost-recovery mechanisms are in place, staff should have a financial interest in the success of the programme. ${ }^{10}$

\section{Cost}

Cost is a barrier, and it was the most frequently quoted obstacle in Nigeria ${ }^{7}$ and Nepal. ${ }^{5}$ The costs of surgery include not only the price of the operation, and the cost of transport to and from the clinic, but also lost income for the carer and the patient. Patients who are willing to attend for surgery may be unable to persuade relatives to accompany them. ${ }^{6}$

However, despite the provision of free transport and treatment, some patients are still unwilling to undergo surgery, ${ }^{6}$ which suggests that poverty may be used as a simple and acceptable explanation when the real barriers are more complex.

\section{Overcoming the cost barrier}

About $80 \%$ of the cost of a cataract operation is related to fixed costs - that is, staff salaries, building depreciation and maintenance, training, etc. These costs are difficult to reduce. However, where there is unused capacity, they will not increase even if the workload grows. This means that the more cataract surgery is performed, the lower the unit cost of each operation. Many eye clinics in poor countries are stuck in a vicious cycle of low surgical volume, leading to a high price for cataract surgery, which deters patients, leading to an even lower number of operations.

The remaining $20 \%$ of the cost is related to consumables, such as eye drops, IOL, and disposable supplies. The cost of these can be reduced to less than $£ 5$ through local manufacture and bulk purchase. ${ }^{11}$

In most communities, patients are willing to pay the equivalent of 1 month's wages for a cataract operation. ${ }^{12}$ This should be the average price for cataract surgery. Poor patients who are unable to pay can be subsidised by increasing the price of surgery for wealthier patients, who pay extra for better accommodation, or a shorter waiting period. This principle of 'tiered pricing' allows cataract surgery to be made available to the maximum number of patients. There are a number of different models of tiered pricing, but all of them are based on an 
assessment of the paying capacity of the population, and setting the price of surgery at an affordable level.

This method of cost recovery has been very effective in India and Nepal. At Lumbini hospital, in Nepal, the annual number of cataract operations increased from 5392 to 14874 in 5 years, and, although $20 \%$ of operations were provided free of charge and another $20 \%$ were subsidised, the hospital's operating profit increased from $\$ 15000$ to $\$ 101000$. $^{12}$

\section{Distance}

In some countries the population is scattered, distances are great, and travel is difficult. In these circumstances it may be necessary to bring the surgery closer to the patient, rather than expecting patients to come to the surgeon.

\section{Overcoming the distance barrier}

The patients who are most remote from eye clinics are usually a long way from any functioning health facility. Alternatively, they may be in 'precarious situations', such as refugee camps, or conflict zones, where it is difficult to establish a permanent eye surgical centre. In these circumstances, it may be necessary for the surgical team to go to the patients, and to use whatever facilities exist - however inadequate they may be. Eye camps have some disadvantages. The surgical outcomes are not as good as surgery performed in a static surgical unit. Cost recovery is difficult. If there are any existing eye care facilities, the sudden arrival of an external surgical team may undermine the local eye workers. Follow-up and treatment of postoperative complications may be impossible.

Although these are serious problems, mobile eye surgical teams may be the only way of reaching some patients, who would otherwise remain blind. If local eye workers are involved in the planning and follow-up, their work will be enhanced rather than undermined. An experienced team of surgeons and nurses, who are used to operating in difficult circumstances, can achieve acceptable surgical results, with a minimal risk of postoperative complications. Although no evidence exists for cataract surgery, a randomised trial has shown that trichiasis surgery may be carried out as safely in the patient's own village as at a health centre, and that performing the operation in the village enhanced the acceptability of surgery. ${ }^{13}$

\section{Supply}

If the barriers of awareness, bad service, cost, and distance can be overcome, the demand for cataract surgery will grow, and the high-volume clinic will have to increase the supply.

\section{Personnel}

Where facilities are limited, there may also be a shortage of trained staff. In most of Africa, there is only one ophthalmologist per million population. ${ }^{14}$ Although India has more ophthalmologists, only a minority are providing cataract surgery in rural areas. Trained nurses and medical assistants are also scarce.

In order to minimise the impact of the shortage of skilled personnel, staff should be used at their maximum level of competence. This means that ophthalmologists should spend their time doing what can only be done by a fully trained ophthalmologist. Routine clerical and administrative tasks are delegated to less highly trained personnel. ${ }^{15}$ This may require more staff rather than less. For example, in the outpatient clinic, registration is carried out by clerical staff. The visual acuity is taken by a health assistant. Routine examination and diagnosis is carried out by health assistants, and the ophthalmologist sees only complex cases. This enables the clinic to see many more patients per day.

In the operating theatre, many tasks can be delegated. In E. Africa, routine cataract surgery is carried out by medical assistants. These ophthalmic clinical officers (OCO) receive 1 year's training in ophthalmology, followed by 1 year of intensive training in cataract surgery, during which they carry out 200 operations (ECCE \& PC-IOL) under supervision. Although there have been no randomised trials to prove that OCO can operate safely, published audits indicate that, with appropriate case selection, their results are as good as the ophthalmologists' outcomes. ${ }^{16}$ The use of nonphysicians to perform cataract surgery is controversial, and is only justified in situations where there are less than four ophthalmologists per million population, and a cataract surgery ratio less than 2000. This means that they are unlikely to be deployed outside Africa.

Ophthalmic assistants can perform many other tasks in the operating theatre. For example, local anaesthesia can be administered by a trained nurse, particularly if the subtenon's route is used. Time between cases can be reduced by using an ophthalmic assistant to prepare the patient, apply a drape, and insert the speculum. At the end of surgery, the ophthalmic assistant gives the subconjunctival injection and applies the dressing, while the surgeon moves on to the next patient, who has already been prepared. Using this system, the median surgical time (time required by the ophthalmologist) per case can be reduced to less than 5 min. $^{11}$

In order to maximise surgical output, the time between surgeries must be reduced, as well as operating time. If 
one surgeon has one operating table, and one nurse assisting, he can perform two operations per hour. If he has two nurses and two tables, so that the next patient is ready before he has finished the previous operation, one surgeon can perform four surgeries per hour. ${ }^{15}$

\section{Surgery}

The use of IOLs has become almost universal, even where facilities are extremely limited. This has been driven by two factors. Firstly, the benefits of IOL use are even greater in poor countries than in wealthy ones (Figure 1). ${ }^{17-19}$ Randomised clinical trials have proven their safety. ${ }^{20,21}$ Secondly, the cost of high-quality IOL has fallen as they are manufactured in developing countries such as India, Nepal, and Eritrea. Single-piece PMMA IOL are available for less than $£ 2$, which is cheaper than aphakic glasses.

In the last decade, there has been a transition from intracapsular cataract extraction to extracapsular. In the absence of $\mathrm{Nd}$ : YAG lasers, there is a risk that posterior capsule opacification will become a significant problem. However, this does not seem to have materialised. ${ }^{22,23}$

In wealthy countries, manual ECCE has been replaced by phacoemulsification, which has been shown to be superior. $^{24}$ The benefits of rapid visual recovery, and low induced astigmatism, are even more important in the developing world. However, a new phaco machine costs $£ 35000$ or more. The use of expensive consumables raises the marginal cost of an operation to unsustainable levels for a poor country.

Sutureless small incision cataract surgery (SICS), first described by Blumenthal in 1994, ${ }^{25}$ may confer the benefits of phacoemulsification, such as rapid visual

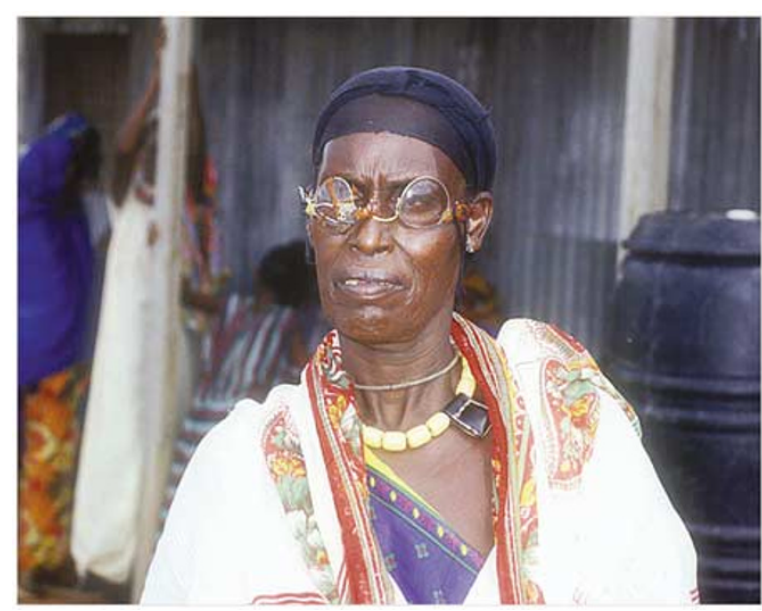

Figure 1 The widespread use of IOL in the developing world should ensure that cataract patients are no longer dependent on do-it-yourself repairs to aphakic spectacles. recovery and reduced astigmatism, without incurring its costs. In Europe and N. America the operation was superseded by phacoemulsification; however, in Asia and Africa there has been a renewal of interest. ${ }^{26}$ The technique requires the construction of a scleral tunnel, approximately $4 \mathrm{~mm}$ long, and 6-8 $\mathrm{mm}$ wide externally. An anterior capsulotomy is performed, and the nucleus is removed from the eye by hydrostatic pressure, or by a hook. Following aspiration of residual soft lens matter, a single-piece PMMA IOL is inserted into the capsular bag. The wound should be watertight without sutures. The technique does not require expensive or complex equipment. It is estimated that the mean cost of consumables (including a rigid PMMA IOL) is between $\$ 5$ and $\$ 7.11,27$ With efficient use of operating theatre personnel, the mean surgical time is between 5 and 12 min. $^{11,27}$

Using this technique $70 \%$ of patients had an uncorrected vision of $6 / 18$ or better at 6 weeks after surgery. With best correction, over $95 \%$ could see $6 / 18{ }^{11}$ A randomised trial showed that $48 \%$ of patients achieved an unaided vision of $6 / 18$ or better 6 weeks after SICS compared to $37 \%$ following conventional ECCE. ${ }^{28}$ The same trial also demonstrated that SICS was no more costly. Including fixed costs, the cost per operation was \$15.82 for standard ECCE and \$15.68 for SICS. ${ }^{27} \mathrm{~A}$ summary of the results of published studies is shown in Table 1.

SICS is technically more difficult than a standard manual ECCE, and it may be contraindicated in some cases. ${ }^{28,29}$ However, with increasing experience, it is possible to perform SICS in well over $90 \%$ of eyes. ${ }^{30}$

There are no published randomised trials comparing SICS with phacoemulsification. If the cost of phacoemulsification falls, and low-cost foldable IOL become available, phaco may become the operation of choice in high-volume clinics in poor countries as well. However, this is unlikely to happen soon. The SICS technique can be used now in any clinic that is currently performing ECCE \& IOL. The additional skills learned

Table 1 Visual outcomes following sutureless small-incision ECCE

\begin{tabular}{|c|c|c|c|c|c|}
\hline \multirow[t]{2}{*}{ Study } & \multirow[t]{2}{*}{ No. of eyes } & \multicolumn{2}{|c|}{$6 / 18+$} & \multicolumn{2}{|c|}{$<6 / 60$} \\
\hline & & $\begin{array}{c}\text { Unaided/ } \\
\text { presenting } \\
(\%)\end{array}$ & $\begin{array}{c}\text { Best } \\
\text { corrected } \\
(\%)\end{array}$ & $\begin{array}{c}\text { Unaided/ } \\
\text { presenting } \\
(\%)\end{array}$ & $\begin{array}{c}\text { Best } \\
\text { corrected } \\
(\%)\end{array}$ \\
\hline Tabin $^{26}$ & 266 & 58.3 & 94.9 & 3.8 & 0.7 \\
\hline Hennig $^{11}$ & 468 & 70.5 & 96.2 & 1.5 & 0.2 \\
\hline Gogate $^{28}$ & 344 & 47.9 & 89.8 & 4.3 & 1.7 \\
\hline Guzek $^{29}$ & 200 & 73.5 & 92.6 & 2.5 & 0.5 \\
\hline
\end{tabular}


for SICS (eg hydrodissection and hydrodelineation) will be a useful foundation for a surgeon's transition to phaco should this become available in the future.

\section{Organisation and administration}

The major obstacles to delivering high-volume cataract surgery are not technical or clinical, but administrative and logistical. Clinics that are organised around a throughput of 10 patients per day are unlikely to be able to deal with 50 per day.

In order to achieve the greatest efficiency, duplication of effort should be avoided, and any unnecessary tasks eliminated. This not only increases the number of patients that can be treated, but also reduces the cost.

One example is routine preoperative investigations. These contribute little to patient welfare, ${ }^{31}$ but are time consuming and expensive. In some clinics the cost of routine preoperative $\mathrm{X}$-rays and blood tests is greater than the cost of the cataract surgery.

Another is patient billing, which may be a complex procedure in which patients are billed for every item, or it can be simplified, with patients charged a single allinclusive fee for cataract surgery. The latter requires little administration, and is transparent, which reduces opportunities for corruption.

In a country with limited eye care facilities, many essential supplies must be imported, or transported to considerable distances within the country. As it may take months for replacement stock to arrive, high-volume clinics need systems in place to give early warning of any imminent shortages.

Managers and administrators who can oversee all these tasks are rare, and the role often devolves to ophthalmologists, which reduces the time they can devote to cataract surgery. Fortunately, training programmes for eye-care managers have now started in India. In future, high-volume clinics will have a manager whose job is to ensure that the ophthalmologist can work as effectively as possible.

A high-volume clinic must ensure high-quality care as well as high quantity. This means monitoring the outcome of surgery. Community-based surveys have shown that up to $40 \%$ of postoperative cataract patients have a presenting vision of less than $6 / 60 .{ }^{32}$ Monitoring outcomes should be built into the care pathway, so that it is an automatic part of cataract surgery. This is associated with an improvement in surgical results. ${ }^{16,33}$

\section{Infrastructure and equipment}

Equipment for use in developing countries should be robust, effective, and simple to maintain. It must also be cheap! Fortunately, instruments and equipment which meet these criteria are increasingly available.

The advent of low-cost portable microscopes has made high-quality ECCE available in the most remote parts of Africa and Asia. Consumables are manufactured at

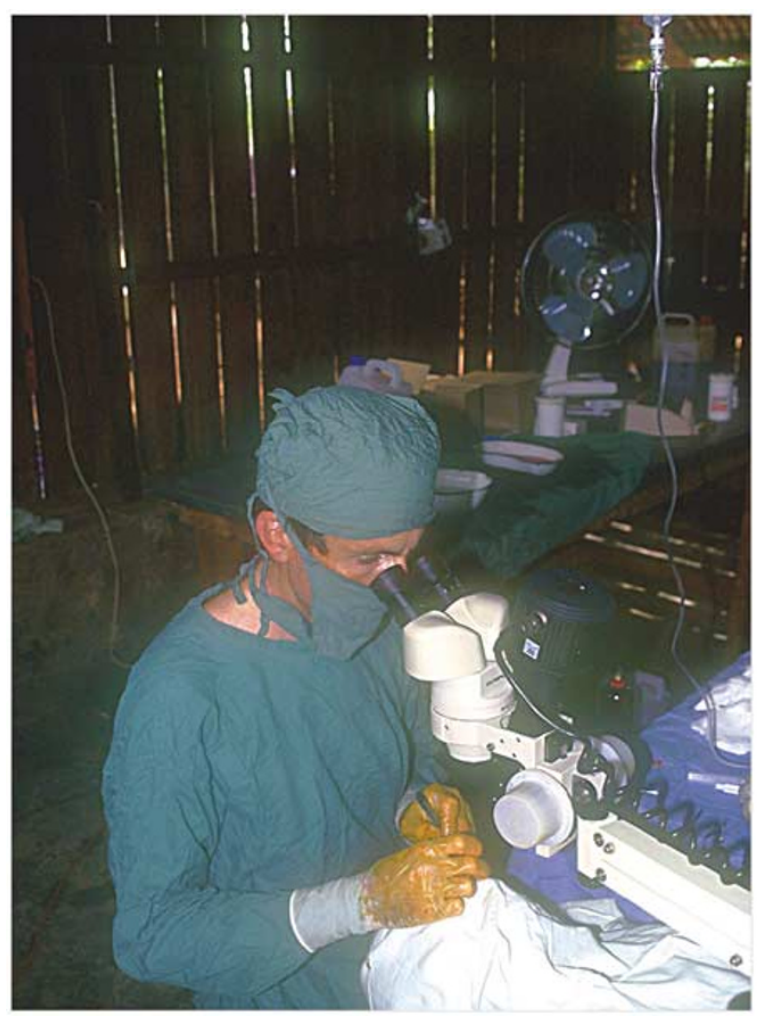

Figure 2 Even in remote situations, the use of a portable microscope and simple instruments can provide good surgical results.

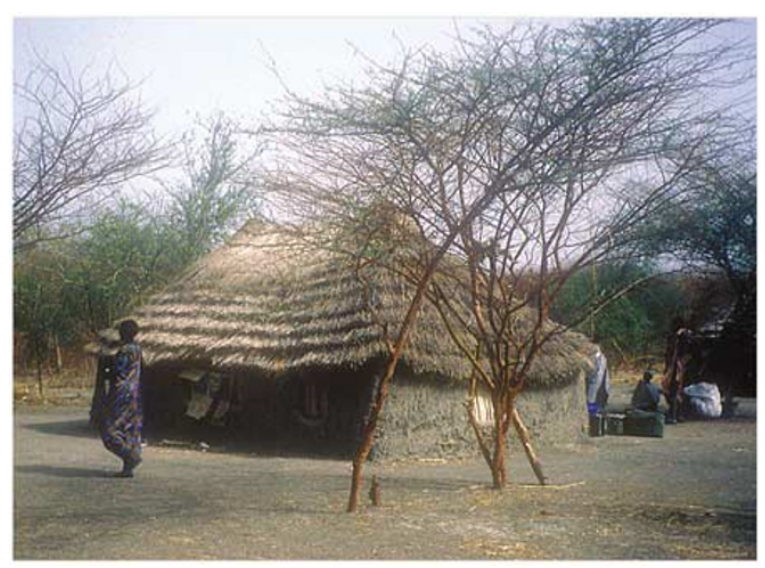

Figure 3 In very remote areas, basic infrastructure is lacking, and surgery must be performed in whatever buildings are available, such as this operating theatre in S. Sudan. 


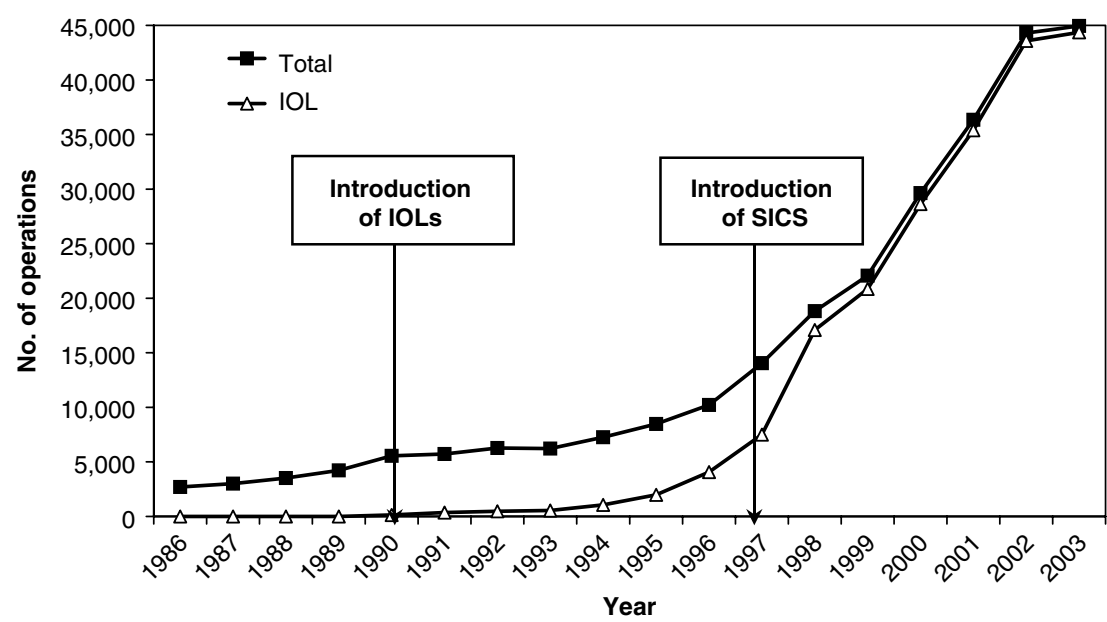

Figure 4 Number of cataract operations at Lahan Hospital, Nepal.

low cost in developing countries, and are exported to other developing countries - a model of South-South collaboration that must be replicated to overcome other health problems. The WHO has produced a Standard List ${ }^{34}$ which details the equipment necessary for cataract surgery. This global standardisation has allowed more bulk purchasing, which has further reduced the cost of surgery.

In an ideal world all eye surgery would take place in a cool, dry, clean, and dust-free environment. Unfortunately the people in greatest need of cataract surgery live in hot, humid, dirty, and dusty places.

It is possible to perform high-volume cataract surgery in difficult circumstances, such as a tent or a mud hut, but it requires meticulous attention to detail (Figures 2 and 3). Maintaining the sterility of the instruments and the operative field is paramount. As autoclaves are heavy and require mains electricity, instruments are disinfected between cases by boiling. The conjunctival sac should be irrigated with $2.5 \%$ povidone iodine prior to local anaesthesia, and again immediately before surgery. In the absence of mains electricity, a portable operating microscope will run off $12 \mathrm{~V}$ batteries, or a small portable generator.

Using these techniques, we have successfully performed thousands of cataract operations in situations such as refugee camps, and conflict zones, where facilities fall far short of the ideal, but no other services are available. Although a high volume is possible under these circumstances, surgery takes longer, and outcomes are less good than when surgery is performed in the base hospital. In the long term, it is always better to develop a network of permanent static facilities, where highvolume surgery is always available.

\section{Conclusions}

In a poor country, high-volume cataract surgery makes the best use of limited resources. In order to provide this level of care, both the demand and supply of cataract surgery must be increased. In addition, the service must offer high-quality care at an affordable price. Experience suggests that where these conditions are met, there will be a rapid growth in the volume of surgery (Figure 4).

\section{References}

1 World Health Organisation. Global initiative for the elimination of avoidable blindness. An informal consultation, WHO/PBL/97.61. Geneva, WHO, 1997.

2 Foster A. Cataract and 'Vision 2020 - the right to sight' initiative. Br J Ophthalmol 2001; 85: 635-637.

3 Brian G, Taylor H. Cataract blindness-challenges for the 21st century. Bull World Health Organ 2001; 79: 249-256.

4 Foster A. Cataract - a global perspective: output, outcome and outlay. Eye 1999; 13(Part 3b): 449-453.

5 Snellingen T, Shrestha BR, Gharti MP, Shrestha JK, Upadhyay MP, Pokhrel RP. Socioeconomic barriers to cataract surgery in Nepal: the South Asian cataract management study. Br J Ophthalmol 1998; 82: 1424-1428.

6 Brilliant GE, Lepkowski JM, Zurita B, Thulasiraj RD. Social determinants of cataract surgery utilization in south India. The Operations Research Group. Arch Ophthalmol 1991; 109: 584-589.

7 Rabiu MM. Cataract blindness and barriers to uptake of cataract surgery in a rural community of northern Nigeria. Br J Ophthalmol 2001; 85: 776-780.

8 Ellwein LB, Lepkowski JM, Thulasiraj RD, Brilliant GE. The cost effectiveness of strategies to reduce barriers to cataract surgery. The Operations Research Group. Int Ophthalmol 1991; 15: 175-183.

9 Dandona L, Dandona R, Shamanna BR, Rao GN. In: Pararajasegaram R, Rao GN (eds). World Blindness and Its Prevention, 6th edn. Hyderabad: International Agency for Prevention of Blindness, 2001, pp 287-295. 
10 Cochrane G. In: Rao GN, Pararajasegaram R (eds). World Blindness and Its Prevention. Hyderabad: International Agency for Prevention of Blindness, 2001, pp 271-277.

11 Hennig A, Kumar J, Yorston D, Foster A. Sutureless cataract surgery with nucleus extraction: outcome of a prospective study in Nepal. Br J Ophthalmol 2003; 87: 266.

12 Green D. In: Pararajasegaram R, Rao GN (eds). World Blindness and its Prevention, 6th edn. Hyderabad: International Agency for the Prevention of Blindness, 2001, pp 277-284.

13 Bowman RJ, Soma OS, Alexander N, Milligan P, Rowley J, Faal $\mathrm{H}$ et al. Should trichiasis surgery be offered in the village? A community randomised trial of village $v$ s health centre-based surgery. Trop Med Int Health 2000; 5: 528-533.

14 Foster A. Who will operate on Africa's 3 million curably blind people? Lancet 1991; 337: 1267-1269.

15 Natchiar G, Robin AL, Thulasiraj RD, Krishnaswamy S. Attacking the backlog of India's curable blind. The Aravind Eye Hospital model. Arch Ophthalmol 1994; 112: 987-993.

16 Yorston D, Gichuhi S, Wood M, Foster A. Does prospective monitoring improve cataract surgery outcomes in Africa? $\mathrm{Br}$ J Ophthalmol 2002; 86: 543-547.

17 Yorston D. Are intraocular lenses the solution to cataract blindness in Africa? Br J Ophthalmol 1998; 82: 469-471.

18 Duerksen R, Limburg H, Carron JE, Foster A. Cataract blindness in Paraguay - results of a national survey. Ophthal Epidemiol 2003; 10: 349-357.

19 Fletcher A, Vijaykumar V, Selvaraj S, Thulasiraj RD, Ellwein LB. The Madurai Intraocular Lens Study. III: Visual functioning and quality of life outcomes. Am J Ophthalmol 1998; 125: 26-35.

20 Prajna NV, Chandrakanth KS, Kim R, Narendran V, Selvakumar S, Ellwein LB et al. The Madurai intraocular lens study. II: Clinical outcomes. Am J Ophthalmol 1998; 125 14-25.

21 Hennig A, Evans JR, Pradhan D, Johnson GJ, Pokhrel RP, Gregson RM et al. Randomised controlled trial of anteriorchamber intraocular lenses. Lancet 1997; 349: 1129-1133.

22 Prajna NV, Ellwein LB, Selvaraj S, Manjula K, Kupfer C. The madurai intraocular lens study. IV: Posterior capsule opacification. Am J Ophthalmol 2000; 130: 304-309.
23 Yorston D, Foster A. Audit of extracapsular cataract extraction and posterior chamber lens implantation as a routine treatment for age related cataract in east Africa. $\mathrm{Br} \mathrm{J}$ Ophthalmol 1999; 83: 897-901.

24 Minassian DC, Rosen P, Dart JK, Reidy A, Desai P, Sidhu M. Extracapsular cataract extraction compared with small incision surgery by phacoemulsification: a randomised trial. Br J Ophthalmol 2001; 85: 822-829.

25 Blumenthal M. Manual ECCE, the present state of the art. Klin Monatsbl Augenheilkd 1994; 205: 266-270.

26 Ruit S, Paudyal G, Gurung R, Tabin G, Moran D, Brian G. An innovation in developing world cataract surgery: sutureless extracapsular cataract extraction with intraocular lens implantation. Clin Exp Ophthalmol 2000; 28: 274-279.

27 Gogate PM, Deshpande M, Wormald RP. Is manual small incision cataract surgery affordable in the developing countries? A cost comparison with extracapsular cataract extraction. Br J Ophthalmol 2003; 87: 843-846.

28 Gogate PM, Deshpande M, Wormald RP, Deshpande R, Kulkarni SR. Extracapsular cataract surgery compared with manual small incision cataract surgery in community eye care setting in western India: a randomised controlled trial. Br J Ophthalmol 2003; 87: 667-672.

29 Guzek JP, Ching A. Small-incision manual extracapsular cataract surgery in Ghana, West Africa. J Cataract Refract Surg 2003; 29: 57-64.

30 Thomas R, Kuriakose T, George R. Towards achieving small-incision cataract surgery $99.8 \%$ of the time. Indian J Ophthalmol 2000; 48: 145-151.

31 Schein OD, Katz J, Bass EB, Tielsch JM, Lubomski LH, Feldman MA et al. The value of routine preoperative medical testing before cataract surgery. N Engl J Med 2000; 342: $168-175$

32 Zhao J, Sui R, Jia L, Fletcher AE, Ellwein LB. Visual acuity and quality of life outcomes in patients with cataract in Shunyi County, China. Am J Ophthalmol 1998; 126: 515-523.

33 Gogate PM, Deshpande M. Monitoring Cataract Outcomes. Presented as a Poster, 7th General Assembly. IAPB, Dubai: International Agency for Prevention of Blindness, 2004.

34 Standard List of Medicines and Equipment for Primary and Secondary Level Eye Care Services. Geneva: World Health Organisation, 2004. 